\title{
Espaço e economia, tempo e valorização : rumo a uma geografia econômica impreterivelmente humana
}

\section{Guilherme Ribeiro}

\section{(2) OpenEdition Journals}

Edição electrónica

URL: http://journals.openedition.org/espacoeconomia/124

DOI: 10.4000/espacoeconomia. 124

ISSN: 2317-7837

Editora

Núcleo de Pesquisa Espaço \& Economia

Refêrencia eletrónica

Guilherme Ribeiro, «Espaço e economia, tempo e valorização : rumo a uma geografia econômica impreterivelmente humana », Espaço e Economia [Online], 2 | 2013, posto online no dia 21 janeiro 2013, consultado o 22 setembro 2020. URL : http://journals.openedition.org/espacoeconomia/124 ; DOI : https://doi.org/10.4000/espacoeconomia.124

Este documento foi criado de forma automática no dia 22 setembro 2020.

(c) NUPEE 


\title{
Espaço e economia, tempo e valorização : rumo a uma geografia econômica impreterivelmente humana
}

\author{
Guilherme Ribeiro
}

1 O segundo número da Espaço e Economia: Revista Brasileira de Geografia Econômica acena com múltiplos temas, abordagens e escalas, explorando de maneira bastante fértil as inúmeras possibilidades contidas neste sub-campo - e, consequentemente, ampliando a esfera de atuação da própria Geografia Humana.

2 De Buenos Aires ao Rio de Janeiro e de Ribeirão Preto a Itaboraí, passando pelo território brasileiro como um todo, são discutidas as novas formas de organização coletiva do trabalho em tempos de reestruturação produtiva e neoliberalismo; o surgimento do futebol como atividade econômica e seus nexos com os transportes e a urbanização; a relação entre os financiamentos públicos e a concentração/ desconcentração regional; a valorização mercantil da natureza e suas funções na constituição urbana; os limites da expansão capitalista e o papel do espaço; os dilemas envolvendo formação profissional e mercado de trabalho.

3 Em 1979, o historiador francês Fernand Braudel nos deixou uma lição que, ao que parece, demorou três décadas para ser compreendida em sua plenitude. Em 0 tempo do mundo, volume final da soberba trilogia Civilização material, economia e capitalismo, lê-se:

"O espaço, fonte de explicação, põe em causa, ao mesmo tempo, todas as realidades da história, todas as partes envolvidas da extensão: os Estados, as sociedades, as culturas, as economias... E, conforme escolhamos um ou outro destes conjuntos, modificar-se-ão o significado e o papel do espaço. Mas não inteiramente." (BRAUDEL, 1979, p.12).

Economistas, historiadores e geógrafos integrantes desta edição executaram suas pesquisas não em nome de paradigmas disciplinares - notadamente insuficientes -, mas sim tendo em vista a relevância do espaço na compreensão da história. História, aqui, 
entendida enquanto a vida humana em geral, com os processos políticos, sociais e econômicos que a constituem. Neste âmbito, o espaço, o território, o regional, o urbano, o bairro e a natureza são estruturas, realidades modificáveis no decorrer do tempo, porém lentamente. Elas atravessam gerações portando consigo as marcas do passado, as intervenções do presente e as utopias para o futuro.

5 Assim, se a fábrica deixou de existir, desfazendo a identidade operária que amalgamava os trabalhadores, o bairro persiste enquanto escala de reprodução da vida cotidiana, e é exatamente a partir dele que surgirão novas formas de cooperação sócio-econômica. Desta forma, o artigo Movimentos sociais, periferia e formas de dominação: dois estudos de caso de economia política e território em Buenos Aires, de Javier Ghibaudi - professor do Departamento de Economia da UFF -, põe em xeque conceitos como exclusão social e segregação territorial, atentando para o fato de que "o bairro da ação organizada, longe de refletir a organização oficial, é uma territorialização construída pelos sujeitos destas ações" (GHIBAUDI, 2013).

Por sua vez, em Políticas territoriais com financiamento públicos. O BNDES a serviço de quem?, Gilberto Oliveira da Silva Jr. incorpora todo o território brasileiro em sua investigação sobre o Banco Nacional de Desenvolvimento Econômico e Social (BNDES). Manejando com habilidade informações quantitativas e análise qualitativa, ele revela a dificuldade do Banco para efetivar a operação de desconcentração regional. Resultado da dissertação de mestrado BNDES: importante ordenador do território brasileiro (SILVA JR., 2004), sua conclusão deve interessar aos estudiosos da economia brasileira: a maior parte do total dos financiamentos do BNDES serviram apenas para aprofundar a hegemonia da Região Sudeste no interior da divisão territorial do trabalho no país (SILVA JR., 2013).

7 Sim: o espaço é revelador e, por que não dizer, reprodutor de desigualdades. Longe de ser algo neutro, tal como a maioria das Ciências Humanas quis supor durante o século XX (vide SOJA, 1993 [1989]), ele é parte integrante da dinâmica de funcionamento do capitalismo, ensina-nos Maurílio Botelho, professor do Departamento de Geociências da UFRRJ. Em Desenvolvimento, espaço e crise estrutural, ele promove uma análise introdutória acerca dos limites da expansão do desenvolvimento capitalista, resgatando tanto autores clássicos como Sweezy e Lênin quanto estudiosos da dinâmica atual do capital como Harvey e Brenner. No seio deste debate, Botelho insere o papel do espaço e, a fim de refletir sobre as contradições do capitalismo, pondera:

"Desde a crise da década de 1970 o capitalismo não foi mais capaz de apresentar um novo ciclo de expansão. Mesmo a descrição da dinâmica capitalista em termos de ciclos não é mais válida, a não ser que estejamos nos referindo aos ciclos de bolhas especulativas. Dizer isso significa dizer que um ou outro país não possa crescer ou mesmo gerar empregos, mas esse crescimento é pontual, individualizado e deve ter explicações específicas - o que significa também que, em geral, mesmo essa geração de emprego pode ocorrer através da substituição de força de trabalho em outras regiões, pois o caso chinês é muito explícito quanto a isso" (BOTELHO, 2013).

Dialogando implicitamente com o texto acima, a problemática da formação profissional e sua íntima ligação com a criação de empregos foi abordada por Taís Ferreira, estudante do Programa de Pós-Graduação em Geografia da UFRJ. Tendo como base empírica a formação do maior investimento da história da Petrobras, o Complexo Petroquímico do Rio de Janeiro (COMPERJ), localizado no município de Itaboraí, tem impactado profundamente seu entorno mesmo antes de sua inauguração. Focalizando seu objeto de pesquisa, em Políticas de qualificação profissional no Leste Metropolitano 
fluminense ela escreve que "Um dos principais desdobramentos das políticas de emprego no Brasil nos últimos anos, diz ela, foi a implementação de políticas de qualificação profissional" (FERREIRA, 2013). Entretanto, uma vez que a reestruturação produtiva alterou sobremaneira a produção, a mão-de-obra e o consumo (vide ANTUNES, 2005 [1995]), nem sempre tais políticas significam emprego para os trabalhadores. Que fazer, então?

É sob uma perspectiva igualmente crítica que Marcos Antônio Silvestre Gomes, professor do Departamento de Geografia da UFF-Campos dos Goytacazes, interroga a criação de parques públicos no texto A espacialização dos parques e a dinâmica da produção, apropriação e valorização do espaço urbano em Ribeirão Preto-SP. Sob o rótulo "integrador" e "harmônico" dos discursos em prol do meio ambiente, o estabelecimento de áreas verdes ocorre precisamente nas áreas mais valorizadas da cidade, contribuindo para o encarecimento das mesmas e, logo, para a segregação urbana como um todo. Conforme Gomes, o interesse não recai sobre a questão ambiental por si só, mas vinculado diretamente aos aspectos político-econômicos. Articulando geografia urbana e geografia econômica, ele faz o seguinte alerta:

"o poder público municipal, ao criar e implantar espaços como parques e praças nos setores onde se localizam os interesses imobiliários, dirigidos às camadas de mais alta renda da cidade, contribui para o aumento do preço dos terrenos, loteamentos e edificações, consolidando o eixo sul-sudeste de Ribeirão Preto como uma área estrategicamente rentável do ponto de vista imobiliário. Neste eixo estão instalados os três shopping centers da cidade, equipamentos urbanos que contribuem para o aumento do preço do solo nestas áreas" (GOMES, 2012).

Compreender o urbano do presente passa, incontornavelmente, pela apreciação do passado: lição básica que muitos geógrafos fazem questão de negligenciar. Como entender qualquer fenômeno fora do processo histórico? Impossível! Nesse sentido, Meios de transporte e dinâmica do futebol no Rio de Janeiro: a ocupação do espaço pelos clubes e ligas cariocas na Primeira República Brasileira, de autoria do professor João Manuel Casquinha Malaia Santos (Universidade Nove de Julho), reveste-se de grande importância. Estamos diante de uma bela leitura da organização interna da cidade sob o prisma do futebol. $\mathrm{O}$ estabelecimento do campeonato carioca está ligado à integração urbana lato sensu; ele dependia da produção do espaço, isto é, transportes, energia, infra-estrutura, mobilidade, acesso aos clubes e, principalmente, dos torcedores, aos estádios. A origem elitista, os entraves econômicos e as barreiras sociais impostas pelos clubes da Zona Sul (Fluminense, Botafogo e Flamengo) eram, por si só, incapazes de constituir um campeonato. Foi necessária, portanto, a participação de clubes da Zona Norte e da Zona Oeste para sua efetivação.

11 Enfim, Espaço e Economia: Revista Brasileira de Geografia Econômica, deseja cumprir sua missão: apresentar aos leitores trabalhos críticos, porém não dogmáticos. À luz de uma geografia econômica ampliada e renovada, apreender as manifestações culturais, políticas e ambientais da vida social. Questionar as fronteiras disciplinares, entendendo que a produção intelectual não deve impor limites ao pensamento e à reflexão. 


\section{BIBLIOGRAFIA}

ANTUNES, Ricardo. Adeus ao trabalho? Ensaio sobre as metamorfoses e a centralidade do mundo do trabalho. 10a ed. São Paulo/Campinas: Cortez/Editora da Unicamp, 2005 (1995).

BOTELHO, Maurílio. Desenvolvimento, espaço e crise estrutural. Espaço e Economia. Revista Brasileira de Geografia Econômica, ano I, n.2 (2013).

BRAUDEL, Fernand. Civilização Material, Economia e Capitalismo: séculos XV-XVIII. Volume 3: O Tempo do Mundo. São Paulo: Martins Fontes, 1996 (1979).

FERREIRA, Taís. Políticas de qualificação profissional no Leste Metropolitano fluminense. Espaço e Economia. Revista Brasileira de Geografia Econômica, ano I, n.2 (2013).

GHIBAUDI, Javier W. Movimentos sociais, periferia e formas de dominação: dois estudos de caso de economia política e território em Buenos Aires. Espaço e Economia. Revista Brasileira de Geografia Econômica, ano I, n.2 (2012).

GOMES, Marcos A.S. A espacialização dos parques e a dinâmica da produção, apropriação e valorização do espaço urbano em Ribeirão Preto-São Paulo. Espaço e Economia. Revista Brasileira de Geografia Econômica, ano I, n.2 (2013).

MALAIA, João Manuel. Meios de transporte e dinâmica do futebol no Rio de Janeiro: a ocupação do espaço pelos clubes e ligas cariocas na Primeira República Brasileira. Espaço e Economia. Revista Brasileira de Geografia Econômica, ano I, n.2 (2013).

SILVA JR., Gilberto Oliveira. BNDES: importante ordenador do território brasileiro. Dissertação de Mestrado. Niterói: Programa de Pós-Graduação em Geografia, UFF (2004).

-- Políticas territoriais com financiamentos públicos. O BNDES a serviço de quem? Espaço e Economia. Revista Brasileira de Geografia Econômica, ano I, n.2 (2013).

SOJA, Edward. Geografias pós-modernas. A reafirmação do espaço na teoria social crítica. Rio de Janeiro: Jorge Zahar (1993 [1989]).

\section{AUTOR}

\section{GUILHERME RIBEIRO}

Doutor em Geografia pela Universidade Federal Fluminense, com doutorado sandwich pela Universidade de Paris - Sorbonne (Paris IV). Pós-Doutor em Geografia pela Universidade Federal de Minas Gerais. Professor Adjunto do Depto. de Geociências da Universidade Federal Rural do Rio de Janeiro. E-mail: geofilos@ig.com.br 